\title{
Evaluation of orphan diseases global burden
}

\author{
Ekaterina V Makarova (1), Ivan S Krysanov (1), Tatiana P Vasilyeva (1), Mikhail D \\ Vasiliev (1), Rena A Zinchenko (2)
}

(1) National Research Institute of Public Health n.a. N.A. Semashko, Moscow, Russia; (2) Research Centre for Medical Genetics n.a. acad. N.P. Bochkov, Moscow, Russia.

This article is distributed under the terms of the Creative Commons Attribution Noncommercial License (CC BY-NC 4.0) which permits any noncommercial use, distribution, and reproduction in any medium, provided the original author(s) and source are credited.

\begin{abstract}
Orphan diseases is a significant socio-economic burden for both global and Russian health care systems. The global burden of disease metrics introduced by WHO, such as DALY, QALY, HALE, can be a useful tool for building economic models and prognoses, as well as medicine funding distribution. However, it is very difficult to standardize a heterogeneous group of rare diseases and it is difficult to talk about the cost-effective treatment options search, in cases where patients with an orphan disease may have only one pathogenetic therapy option. Much work needs to be done to find optimal treatment options and establish the standards of care necessary to maintain physical health, work capacity and quality of life.
\end{abstract}

Key Words: Orphan diseases; rare diseases; global disease time; disability; quality of life; DALY; QALY; HALE.

Eur J Transl Myol 2020; 31 (2): 9610. doi: 10.4081/ejtm.2021.9610

Modern world is changing rapidly and dynamically whit increasing population and duration of life. In these conditions, maintenance of a person's legal capacity and quality of life is of particular importance. Thanks to modern advances in medical science, it has become possible to reduce mortality and to treat or compensate for diseases previously considered incurable. These undoubtedly positive changes, nevertheless, are associated with increasing number of patients with functional limitations, of burden on health care and difficulties in budget planning. Country leaders, ministries and public organizations have a serious interest in maintaining health of citizens and their ability to work, both for ethical and financial reasons. That is why today socio-demographic characteristics are carefully studied and analyzed, which make it possible to form impression of the health of the population, to assess contribution of individual diseases to permanent and temporary disability, the so-called global burden of disease (GBD). GBD - is the basis for compiling economic models, forecasting spending and distributing financial resources in health care. ${ }^{1}$ Unfortunately, information on mortality and health of the population in all regions of the world is very fragmentary and quite contradictory. This highlights the need to use common terms, metrics and criteria to describe and analyze public health problems and burden of different diseases, injuries and risk factors. Introduction of common framework for collecting, integrating, validating, analyzing, and benchmarking data would be of great benefit. Availability of objective and comprehensive data on socially significant GBD indicators would give the authorities not only the opportunity to comprehensively consider the current picture and emerging trends in the health status of the population, but to implement effective programs to preserve health and to eliminate identified problems.

\section{Orphan diseases}

Orphan diseases are an important problem of modern healthcare that requires a special approach and careful budget planning. "Orphan", or rare diseases, - is an umbrella term for a group of nosologies that are less common than the frequency established by the legislation of each country. ${ }^{2,3}$ There is no standard definition of a rare disease; on average, a disease is considered rare if it affects fewer than 7 out of 10.000 people in the population. According to the existing requirements in Russia, orphan diseases are diseases whose prevalence is within 10 cases per 100000 persons. $^{2}$ In the countries of the European Union, the disease is considered rare if it affects less than 1: 2000 of population, in the USA - less than 1: 200000 of the population, in Japan - less than 4: 10000 people., ${ }^{4,5}$ Between 5000 and 8000 rare diseases have been identified in the world, about $80 \%$ of them are of genetic origin. 


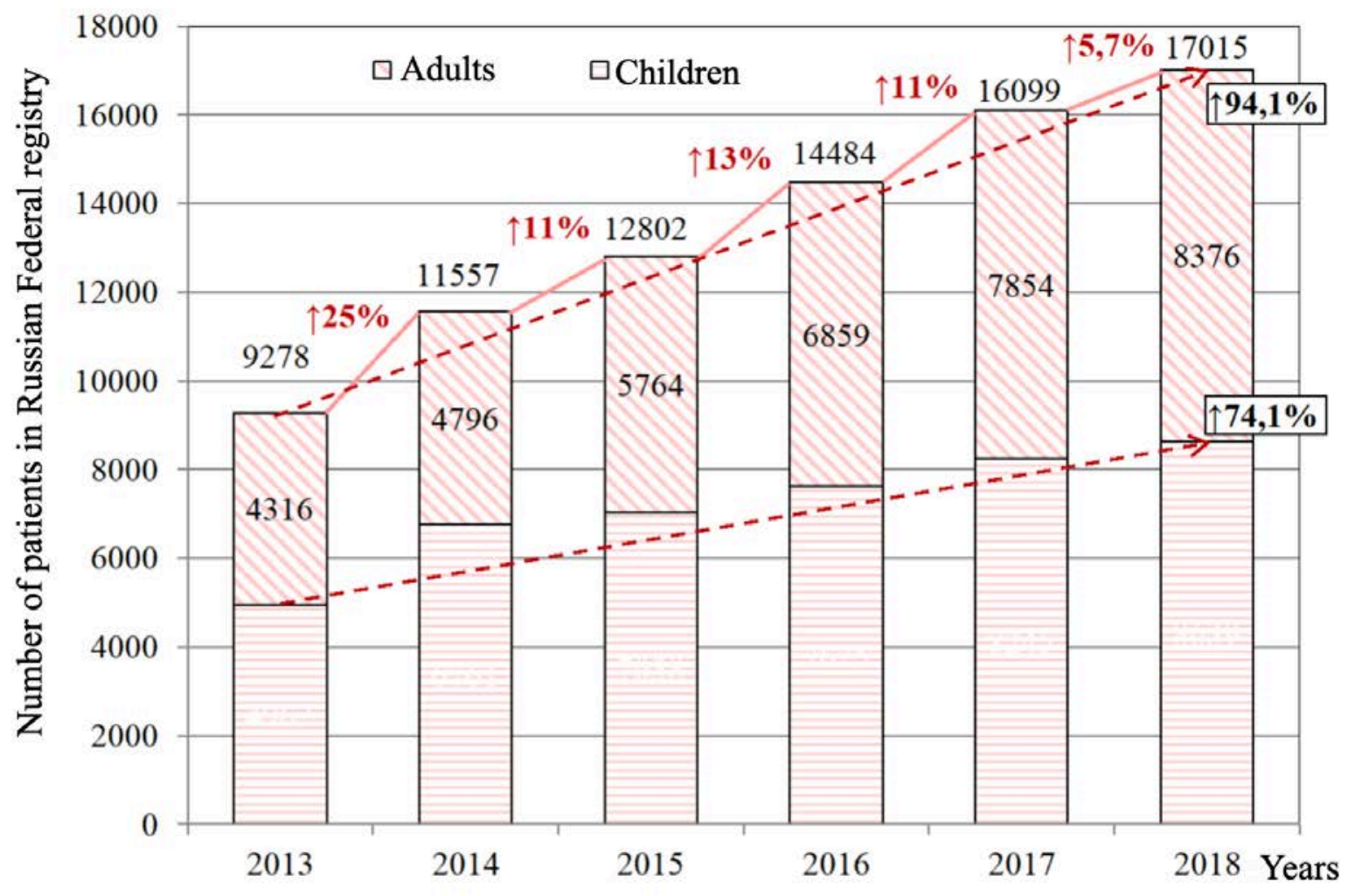

Fig 1. Increase in the number of patients with rare diseases in Russian Federal Registry.

Although the peculiarity of these diseases is that they have a low incidence, they are numerous and their overall share in the statistics of disability and mortality is very high. Consequently, the socio-economic burden of orphan pathology for society and the state is also high.,4 In Russia, at the end of 2019, the list of rare diseases, whose treatment is covered by the state, was expanded to 14 conditions (hemophilia, cystic fibrosis, pituitary dwarfism, Gaucher disease, malignant neoplasms of lymphoid, hematopoietic and related tissues, multiple sclerosis, hemolytic uremic syndrome, juvenile arthritis with systemic onset, mucopolysaccharidosis I, II and VI type II, hereditary anemia, non-aplastic factors (fibrinogen), VII (labile), X (Stuart-Prower), ${ }^{5}$ and budgetary funding was increased yearly to 2 billion rubles (32.300000 USD) as of December 2019. Comparative analysis of the dynamics of the prevalence of rare (orphan) diseases in children, both in general and by individual nosological forms according to 2015 and 2018 data, showed that the prevalence of rare (orphan) diseases in children as a whole increased from 234.76 to 283.65 per 1000000 of the child population (by 20.8\%) (1: 4250 and 1: 3520, respectively). This happened due to the majority of nosological forms (Figure 1 and Tables 1 and 2). ${ }^{6}$ Depending on the type of disease, a monthly course of treatment and / or rehabilitation costs from 100.000 rubles (1400 USD) up to several million of rubles. ${ }^{6}$ The cost of orphan drugs, according to European colleagues, exceeds the cost of conventional drugs by 13.8 times. $^{7}$ Due to the local and small sales market, it is not profitable for pharmaceutical companies to develop new drugs and spend them on clinical trials. For very few rare diseases, specific drugs have been developed, although the use of specific therapy can significantly affect the disability, mortality and quality of life of such patients. $^{2}$ There are practically no data on the economic burden and global health indicators in people with rare diseases in Russian scientific sources. As an example, we can take the data on hemophilia A: the course of treatment for which for a child ranges from 21040 USD to 1000000 USD per year per patient, and for an adult from 42700 USD to 2140000 USD per year per patient. The cost varies depending on the drug, weight, type of disease and the presence of complications. ${ }^{8}$ Kolbin A.S. et al. (2018) ${ }^{9}$ provides figures for the cost of treating Pompe disease. The cost of providing patients with the specific drug alglucosidase alfa as enzyme replacement therapy for a child is 10131952 rubles or 131264 USD per year per patient, and for an adult 34596912 rubles or 448219 USD per year per patient. At the same time, it 
Evaluation of orphan diseases global burden

Eur J Transl Myol 2021; 31 (2): 9610. doi: 10.4081/ejtm.2021.9610

Table 1. Absolute numbers of patients and prevalence (per 100.000) of the most common rare diseases in Russia (according to Russian Federal Register)

\begin{tabular}{|c|c|c|c|c|c|}
\hline \multirow[t]{2}{*}{ Disease } & \multirow[t]{2}{*}{ IDC-10 } & \multicolumn{2}{|c|}{$\begin{array}{l}\text { Number of patients with orphan } \\
\text { diseases in Russia (according } \\
\text { Federal Registry) }\end{array}$} & \multirow{2}{*}{$\begin{array}{l}\text { Prevalence in } \\
\text { Russia (per } 100 \\
\text { 000) in } 2019\end{array}$} & \multirow{2}{*}{$\begin{array}{l}\text { Prevalence } \\
\text { abroad } \\
\text { Russia * }\end{array}$} \\
\hline & & 2015 & 2019 & & \\
\hline $\begin{array}{l}\text { Hemolytic uremic } \\
\text { syndrome }\end{array}$ & D59.3 & 205 & 407 & 0.28 & $0.1-0.9$ \\
\hline $\begin{array}{l}\text { Paroxysmal nocturnal } \\
\text { hemoglobinuria } \\
\text { (Markiafava-Micheli) }\end{array}$ & D59.5 & 289 & 380 & 0.26 & $1-9$ \\
\hline $\begin{array}{l}\text { Aplastic anemia, } \\
\text { unspecified }\end{array}$ & D61.9 & 709 & 1078 & 0.73 & $0.1-0.9$ \\
\hline $\begin{array}{l}\text { Hereditary deficiency of } \\
\text { factors II, VII, X }\end{array}$ & D68.2 & 139 & 225 & 0.15 & 0.1-0.9 \\
\hline $\begin{array}{l}\text { Idiopathic } \\
\text { thrombocytopenic purpura } \\
\text { (Evans syndrome) }\end{array}$ & D69.3 & 2860 & 4002 & 2.72 & $5-10$ \\
\hline $\begin{array}{l}\text { Defect in the complement } \\
\text { system }\end{array}$ & D84.1 & 117 & 327 & 0.22 & $1-9$ \\
\hline $\begin{array}{l}\text { Premature puberty of } \\
\text { central origin }\end{array}$ & E22.8 & 564 & 936 & 0.64 & $0.8-3.2$ \\
\hline $\begin{array}{l}\text { Disorders of aromatic } \\
\text { amino acid metabolism } \\
\text { (classical phenylketon uria, } \\
\text { other types of } \\
\text { hyperphenylalaninemia) }\end{array}$ & $\begin{array}{c}\mathrm{E} 70.0 \mathrm{E} 70 \\
.1\end{array}$ & 3678 & 4775 & 3.25 & $5-10$ \\
\hline Tyrosinemia & E70.2 & 20 & 33 & 0.02 & $0.1-0.9$ \\
\hline Maple Syrup Disease & E71.0 & 11 & 19 & 0.01 & $0.1-0.9$ \\
\hline $\begin{array}{l}\text { Other types of branched- } \\
\text { chain amino acid } \\
\text { metabolism disorders } \\
\text { (isovalerian acidemia, } \\
\text { methyl malonic acidemia, } \\
\text { propionic acidemia) }\end{array}$ & E71.1 & 20 & 31 & 0.02 & $0.1-0.9$ \\
\hline
\end{tabular}

was concluded that the use of a specific drug is an economically feasible treatment option being $11.4 \%$ cheaper in comparison with symptomatic therapy. The costs of the health care system due to the progression of the disease and severe complications in patients with Pompe disease up to 12077545 rubles or 156470 USD per person lower when using alglucosidase alfa. On the contrary, the increase in the costs of diagnostic and rehabilitation measures in patients on symptomatic therapy determines a significant burden on the budget of medical institutions, given the severity of the course and the deterioration of patients' condition. ${ }^{9}$ Moreover, this is just a small fraction of the numbers and needs of patients with rare diseases. According to various estimates, from 15000 to 1.5 million people in Russia suffer from orphan pathology. 5,6 Such a scatter of figures is due to the 
Table 2. Absolute numbers of patients and prevalence (per 100 000) of the most common rare diseases in Russia (according to Federal Register)

\begin{tabular}{|c|c|c|c|c|c|}
\hline $\begin{array}{l}\text { Fatty acid metabolism } \\
\text { disorders }\end{array}$ & E71.3 & 30 & 60 & 0.04 & $1-9$ \\
\hline Homocystinuria & E72.1 & 15 & 26 & 0.02 & $1-9$ \\
\hline Glutaricaciduria & E72.3 & 40 & 36 & 0.02 & $0.1-0.9$ \\
\hline Galactosemia & E74.2 & 267 & 421 & 0.29 & 0.21 \\
\hline $\begin{array}{l}\text { Other sphingolipidosis: } \\
\text { Fabry (Fabry-Anderson) } \\
\text { disease, Niemann-Pick }\end{array}$ & E75.2 & 66 & 141 & 0,10 & $1-9$ \\
\hline $\begin{array}{l}\text { Mucopolysaccharidosis, } \\
\text { type I }\end{array}$ & E76.0 & 66 & 101 & 0.07 & $0.1-0.9$ \\
\hline $\begin{array}{l}\text { Mucopolysaccharidosis, } \\
\text { type II }\end{array}$ & E76.1 & 98 & 121 & 0.08 & $0.9-1.6$ \\
\hline $\begin{array}{l}\text { Mucopolysaccharidosis, } \\
\text { type VI }\end{array}$ & E76.2 & 46 & 53 & 0.04 & $0.1-0.9$ \\
\hline $\begin{array}{l}\text { Acute intermittent (hepatic) } \\
\text { porphyria }\end{array}$ & $\mathrm{E} 80.2$ & 50 & 100 & 0.07 & $1-5$ \\
\hline $\begin{array}{l}\text { Copper metabolism } \\
\text { disorders (Wilson's disease) }\end{array}$ & E83.0 & 602 & 811 & 0.55 & $1-9$ \\
\hline $\begin{array}{l}\text { Incomplete (imperfect) } \\
\text { osteogenesis }\end{array}$ & Q78.0 & 560 & 736 & 0.50 & $5-10$ \\
\hline $\begin{array}{l}\text { Pulmonary (arterial) } \\
\text { hypertension (idiopathic) } \\
\text { (primary) }\end{array}$ & I27.0 & 519 & 749 & 0.51 & $1-9$ \\
\hline $\begin{array}{l}\text { Systemic-onset juvenile } \\
\text { arthritis }\end{array}$ & M08.2 & 1058 & 1406 & 0.96 & $1-9$ \\
\hline Total & & 12029 & 16973 & 11.56 & \\
\hline
\end{tabular}

* Prevalence data abroad is derived from information provided by European Orphanet Information System (2019). ${ }^{3}$

difficulties of the epidemiological assessment of this group of diseases, due to its heterogeneity, difficulties in diagnosis and statistical accounting for public health. Walker C.E. et al. (2016) made an attempt to assess the problem of the global burden of rare diseases for Australia, when analyzing medical databases, 441 rare disease codes and a cohort of 45213 people with these diagnoses were identified. This represented approximately 2\% of the population of Western Australia. Walker and colleagues also calculated the impact of rare diseases on the Australian health system: hospital stays associated with rare diseases were on average 3 days longer than the average hospital stay. Two percent of the population suffering from rare diseases accounted for 4.6 to $10.5 \%$ of total hospitalization costs. ${ }^{10}$ The American researchers confirm these results. Yoon et al. ${ }^{11}$ report that codes of birth defects and genetic diseases accounted for $2.5 \%$ of childhood diseases and accounted for 9 to $12 \%$ of hospital admissions to pediatric departments, which corresponded to 16 to $28 \%$ of total costs of inpatient treatment. In pediatric practice, rare diseases are believed to account for a higher proportion of hospitalizations and costs than adults do. Research data from Walker C.E. confirm this hypothesis. The work of his colleagues can be extrapolated to other health care systems for rare diseases. ${ }^{11}$ 


\section{The Global Burden of Disease}

In 1990, the World Health Organization (WHO), together with the World Bank, initiated the Global Burden of Disease (GBD) project. ${ }^{12,13}$ The purpose of those studies were to solve three main tasks: i) Provide information on non-fatal disease outcomes for international health policy discussion; ii) Develop objective epidemiological assessment criteria; iii) Quantify the burden of disease and its economic significance. A number of metrics have been introduced as quantitative assessment criteria. One of the main ones was QALY (quality adjusted life-years) - years of life adjusted for quality. QALY is a score calculated to compare different diseases and health interventions, which takes into account the average quality of life expectancy. For example, one year of ideal health equals one QALY, deaths equals zero QALY, and a year lived in a worse than ideal condition is graded from 0 to 1 . The cost of QALYs for each individual nosology is of great importance for the distribution of health care resources. DALY (Disability adjusted life-years) - years of life adjusted for disability, has become another concept for assessing global health in research. One DALY represents one wasted year of healthy life. DALY indicator can be viewed as the gap between the current state of health and the ideal situation when the entire population survives to old age, without limiting its functionality. For illness, condition or injury, DALYs are calculated as the sum of years of life lost (YLL) due to premature mortality of lost years due to disability (YLD). Thus, DALY = YLL + YLD. YLL is the number of deaths from a specific disease times the average life expectancy. YLL considers cause of death, age and gender. $\mathbf{Y L L}=\mathbf{N} \times \mathbf{L}$, where: $\mathbf{N}=$ number of deaths and $\mathrm{L}=$ average life expectancy in years. To determine the YLD for a specific condition over a certain time period, the number of cases of the disease in that period is taken, multiplied by the average life expectancy with this disease and a coefficient reflecting the severity of the disease on a scale from 0 (ideal health) to 1 (death). Basic formula for YLD is: YLD = I x DW $\mathbf{x}$ L, where: $\mathrm{I}=$ number of cases, DW = weight of disability, $\mathrm{L}=$ mean duration of illness before remission or death (years). Examining current DALYs and their dynamics allows you to quickly compare the burden of different diseases and injuries. For a complete picture, the researchers additionally use the opposite parameter - HALE (Healthy Life Expectancy), which reflects the expected healthy life expectancy and is calculated using the Sullivan method. ${ }^{12}$ HALE is a single aggregate indicator of population health expressed in years lived to death without disease and functional limitations. In 2016, this indicator, averaged over the world, was 63.3 years. ${ }^{13}$ It is the most significant for assessing global human health. Together, the DALY and HALE scores allow comparisons of the extent of functional health loss due to illness and injury across countries and across different social groups. They can be used to assess the effectiveness of health systems and understand the needs of the population in providing medical care. In Russia for 2016 the HALE indicator was 66.09 (61.24 - 70.37) years for women and 57.78 (53.22 - 62.52) years for men, which is on average two years more than in 1990 and about 10 years less than the average life expectancy for men and women. ${ }^{14}$

\section{Global burden of orphan diseases assessment}

Estimating the global burden of orphan diseases is challenging. The existing criteria for assessing the global burden of disease are poorly applicable to rare pathologies, primarily for a number of technical reasons. ${ }^{13}$ Clearly identify and count the rare disease is a daunting task. Significant difficulties arise already at the stage of collecting statistical data, due to problems with the accuracy of the final diagnosis, imperfections in registers and reporting systems. In addition, different countries have adopted different definitions of a "rare disease"; new conditions are detected every year, which add to the list, while others may go off the list due to an increase in prevalence. Thus, due to the heterogeneity of the group of orphan diseases itself, all epidemiological data and global estimates are very approximate. ${ }^{15}$ The possibilities for using GBD metrics are quite narrow. For example, the formulas do not take into account the stages of the disease and the long-term prospects of its development, do not assess the economic benefit that can be obtained through early treatment, which will exceed (for example, type 1 Gaucher disease) expensive blood transfusions, splenectomy, pain relief, hospitalizations, endoprosthetics and other operations at a later age. While these procedures themselves are considered costeffective for the untreated patient, they can be very costly for the healthcare system. ${ }^{16}$ Splenectomy, in particular, impairs the long-term perspective by increasing the incidence of disability and increasing the risk of osteonecrosis. ${ }^{17}$ GBD metrics ignore the economic benefits of early, effective treatment that allows the patient and family to participate in working life. As calculated by Dr. Hyru and colleagues, ${ }^{17}$ a young married specialist with a diagnosis of type 1 Gaucher disease, who is in his twenties, undergoing enzyme replacement therapy, together with his wife, will bring about 100000 British pounds a year to the state in tax payments, which will fully cover the cost of the medicine. Thus, we would like to emphasize not only the ethical underpinnings of effective treatment, but also the savings that healthcare can receive.

\section{Ethical issue of application of global burden of disease metrics in patients with Orphan Pathology}

Speaking of rare diseases, it is difficult to use standard metrics for assessing GBD for a number of ethical reasons, as it forces one to think in accordance with a utilitarian approach and puts financial benefits as its goal, which inevitably pushes the value of human life and its quality to second place. According to British researchers, for example, the cost of 15 years of therapy for one 
patient with Pompe disease 2500000 British pounds (3460337 USD) is equal to the cost of 520 arthroplasty surgeries, which implies a greater benefit in the treatment of complications of the disease, in comparison with the appointment of pathogenetic therapy. The DALY and QALY metrics do not take into account the relative safety of treatment: for example, a QALY analysis will help guide the choice of bone marrow transplantation in Gaucher disease, but this manipulation can be fatal when compared to safe and effective enzyme infusions. Based on the cost of QALYs, NICE would have to choose risky bone marrow transplant over specific therapy for Gaucher disease (costing between 380000 British pounds and 476000 British pounds (525971 USD and 658848 USD) per QALY, depending on genotype). However, NICE recommended the latter, abandoning the costeffective approach. A significant difficulty in the case of rare pathologies is that GBD metrics are typically used for comparative economic assessments of different medical intervention options. But many orphan diseases have a single drug for specific therapy, or are treated exclusively symptomatically. Thus, it is not correct to assess the benefits of the only option for medical care. GBD-based economic models are not transparent enough and are often used in a discriminatory manner in terms of age, favoring young people who can live longer and have greater capacity to act, while giving less value to the lives of children and the elderly. This is typical for the DALY and QALY. The WHO Working Group recognizes that its matrix also requires significant refinement. For these reasons, law from using cost-benefit analysis to make treatment decisions prohibits insurance companies in the United States. The idea of the high cost of treating orphan diseases also may not always correspond to reality, since over time and with the development of technology, the price can change. Medicine does not refuse transplant operations for reasons of economic efficiency, although recipients have a shorter life expectancy and high costs for a course of immunosuppressive drugs and treatment of complications. When transplantation only began to enter clinical practice, this method was negatively assessed as radical and expensive, but now it is the standard widespread treatment option. Assessing the quality of life and standardizing this parameter is convenient, but one person is not able to estimate the quality of life of another person accurately. People do not understand well the quality of life of others. Thus, the expression of the quantity and quality of human life in economic units sets the price for human life, belittles their individuality and objectifies people. Therefore, the utilitarian approach should not be applied to people, since it levels out someone else's pain or limitations. A person is not quantifiable by his usefulness and a shift in emphasis on "cost recovery" will rather lead to a deterioration in public health, which is more than an improvement in the results of treatment of patients taking orphan drugs. There is a lack of evidence and long-term data on safety and efficacy in the treatment of many orphan diseases compared to more studied conditions, as the results of decades of research are often not used for orphan conditions. Much of the debate about health priorities takes the following form: "Patients A and B need $100 \mathrm{ml}$ of medicine, while Patient C $200 \mathrm{ml}$. Should we treat A and B or C?" - this is unfair because for many people in need of life-saving therapy, the effective dosage and cost are morally completely arbitrary. After all, the amount of medicine they need and its cost did not directly skyrocket from them. Perhaps the only adequate question, regardless of cost and dosage, is: whether the drug can improve health or at least stabilize the manifestations of the disease? If yes, the drug must be covered for all three patients A, B and C.

\section{Russian government policies, problems and solutions}

In Russian Federation 14 nosologies are included to the «Register of patients with life-threatening and chronic progressive rare (orphan) diseases leading to a reduction in the life expectancy of citizens or their disability», treatment of these patients comes at the expense of the federal budget. Among these patients, there are no priorities in age, type or stage of the disease for medical care and drug provision. In accordance with the legislation, all patients must receive treatment. ${ }^{5,6}$ In the cases of nosologies that are out of federal budget (on regional budget) and lack of available funds in this region a responsible person should find sources of budgets that will provide patients with the necessary therapy for the required period. It is possible to use territorial obligatory medical insurance funds or apply individually to the federal budget. When the problem is understood correctly by all participants, the issue of drugs provision to the patient with rare disease is always resolved. ${ }^{5,6}$ Since 2021, on behalf of the president of Russian Federatoin, state fund is being formed and by increasing the tax rate on personal income for citizens whose income exceeds five million rubles a year from $13-15 \%$, the $2 \%$ received will be targeted for financing patients with orphan diseases. This structure is being created currently and the whole mechanism is worked out. Supervisory council is planned in this structure for financing mechanism control and funds distribution monitoring. Integrated work and information exchange with charitable foundations, who provide assistance for patients with orphan diseases and interaction with the subjects of Russian Federation, are essential for the targeted financing mechanism in patient with rare diseases.

\section{Conclusions}

Orphan diseases represent a significant social and economic burden for both global and Russian healthcare. The global burden of disease metrics introduced by WHO, such as DALY, QALY, HALE, can be a useful tool for building economic models and projections, as well as allocating funding in medicine. However, it is difficult to standardize a heterogeneous group of rare diseases and it is difficult to talk about finding cost- 
effective treatment options in cases where patients with a number of orphan diseases have only one pathogenetic therapy option. A large amount of work must be done to find the optimal treatment options and form the standards of medical care necessary to maintain the physical health, ability to work and the quality of life of patients with orphan diseases.

\section{List of acronyms}

DALY - disability adjusted life years

GBD - global burden of disease

HALE - healthy life expectancy

WHO - World Health Organization

QALY - quality adjusted life years

\section{Author contributions}

EM, article text; IK, idea and concept of the review; TV, informational support; MV, bibliographical search; RZ, scientific consultant;

\section{Acknowledgments}

The Authors thank colleagues of the Departments of Biomedical Sciences and Neurosciences, University of Padova, Italy and of the A\&C M-C Foundation for Translational Myology, Padova, Italy for discussion and critical readings.

\section{Funding None}

\section{Conflict of Interest}

The authors declare they have no financial, personal, or other conflicts of interest.

\section{Ethical Publication Statement}

We confirm that we have read the Journal's position on issues involved in ethical publication and affirm that this report is consistent with those guidelines.

\section{Corresponding Author}

Ekaterina Vladimirovna Makarova, Senior Research Scientist, FSSBI “N.A. Semashko National Research Institute of Public Health”, 105064, st. Vorontsovo Field, 12 / 1c1, Moscow, Russia. Phone +7 9151114137.

ORCID iD: 0000-0003-2970-6309

E-mail: rue-royal@inbox.ru

\section{E-mails and ORCID iD of Coauthors}

Ivan S Krysanov: krysanov-ivan@mail.ru ORCID iD: 0000-0002-3605-8592

Tatiana P Vasilyeva: vasileva tp@mail.ru

ORCID iD: 0000-0002-3605-8592

Mikhail D Vasiliev: m.vasilev@mail.ru

ORCID iD: 0000-0003-1646-7345

Rena A Zinchenko: renazinchenko@mail.ru

ORCID iD: 0000-0003-3586-3458

\section{References}

1. Global burden of disease: Generation of evidence, policy direction. Health Metricsand Evaluation (IHME). University of Washington, Human
Development Network, World Bank. Washington DC. 2013. 46 p. ISBN 978-0-9894752-5-9.

2. Kosyakova NV, Gavrilina NI. Orphan diseases history of the issue and modern view of the problem. Modern problems of science and education. 2015; 2.

3. Orphanet Report Series - Prevalence of rare diseases: Bibliographic data - January 2020 Number 1. Available at: http://www.orpha.net/ orphacom/cahiers/docs/GB/Prevalence_of_rare_di seases_by_alphabetical_list.pdf

4. European Medicines Agency Annual report on the use of the special contribution for orphan medicinal products (2019) Available at: https://www.ema. europa.eu/en/documents/annual-report/annualreport-use-special-contribution-orphan-medicinal products-2019_en.pdf.

5. Volkova N.S., Aksu E. Rare (orphan) diseases: legal regulation in Russia and abroad. Journal of Foreign Law and Comparative Law. 2018; 4 (71)

6. Vasilieva TP, Zinchenko RA, Komarov IA, Krasilnikova EYu, Aleksandrova OYu, Konovalov G., Kutsev SI. The prevalence and diagnosis of rare (orphan) diseases in pediatric population of the Russian Federation. Pediatria n.a. G.N. Speransky. 2020; 99 (4): 229-237. doi: 10.24110/0031-403X2020-99-4-229-237.

7. Picavet E, Morel T, Cassiman D, Simoens S. Shining a light in the black box of orphan drug pricing. Orphanet J Rare Dis. 2014 Apr 27;9:62. doi: 10.1186/1750-1172-9-62.

8. Yagudina RI, Molchanova NB. Analysis of healthcare system costs for drug therapy for patients with hemophilia A based on treatment standards, clinical guidelines and selected drug groups. Quality assurance issues for medicines. 2016; 3 (13): 29-41.

9. Kolbin AS, Vilyum IA, Proskurin MA, Balykina YE. [Pharmacoeconomic analysis of using mirabegron to treat overactive bladder in the setting of the Russian Federation health care]. Urologiia. 2016 Feb;(1):32-39. Russian.

10. Walker CE, Mahede T, Davis G, Miller LJ, Girschik J, Brameld K, Sun W, Rath A, Aymé S, Zubrick SR, Baynam GS, Molster C, Dawkins HJS, Weeramanthri TS. The collective impact of rare diseases in Western Australia: an estimate using a population-based cohort. Genet Med. 2017 May;19(5):546-552. doi: 10.1038/gim.2016.143. Epub 2016 Sep 22.

11. Yoong SL, Hall A, Williams CM, Skelton E, Oldmeadow C, Wiggers J, Karimkhani C, Boyers LN, Dellavalle RP, Hilton J, Wolfenden L. Alignment of systematic reviews published in the Cochrane Database of Systematic Reviews and the Database of Abstracts and Reviews of Effectiveness with global burden-of-disease data: a bibliographic analysis. J Epidemiol Community Health. 2015 
Jul;69(7):708-14. doi: 10.1136/jech-2014-205389. Epub 2015 Apr 17.

12. Vallabhaneni S, Mody RK, Walker T, Chiller T. The Global Burden of Fungal Diseases. Infect Dis Clin North Am. 2016 Mar;30(1):1-11. doi: 10.1016/j.idc.2015.10.004. Epub 2015 Dec 29.

13. WHO methods and data sources for global burden of disease estimates 2000-2016. Available at: https://www.who.int/healthinfo/global_burden_dis ease/GlobalDALY_method_2000_2016.pdf

14. GBD 2016 DALYs and HALE Collaborators. Global, regional, and national disability-adjusted life-years (DALYs) for 333 diseases and injuries and healthy life expectancy (HALE) for 195 countries and territories, 1990-2016: a systematic analysis for the Global Burden of Disease Study 2016. Lancet. 2017 Sep 16;390(10100):1260-1344. doi: 10.1016/S0140-6736(17)32130-X. Erratum in: Lancet. 2017 Oct 28;390(10106):e38.

15. Hyry HI, Stern AD, Cox TM, Roos JC. Limits on use of health economic assessments for rare diseases. QJM. 2014 Mar;107(3):241-5. doi: 10.1093/qjmed/hcu016. Epub 2014 Jan 22.

16. Kontoghiorghe CN, Andreou N, Constantinou K, Kontoghiorghes GJ. World health dilemmas: Orphan and rare diseases, orphan drugs and orphan patients. World J Methodol. 2014 Sep 26;4(3):16388. doi: 10.5662/wjm.v4.i3.163.

17. Institute of Medicine (US) Committee on Accelerating Rare Diseases Research and Orphan Product Development. Rare Diseases and Orphan Products: Accelerating Research and Development. Field MJ, Boat TF, editors. Washington (DC): National Academies Press (US); 2010. PMID: 21796826.

Submission: January 15, 2021

Revision received: March 2, 2021 Accepted for publication: March 3, 2021 